\title{
Post-Discharge Adverse Events Among Urban and Rural Patients of an Urban Community Hospital: A Prospective Cohort Study
}

\author{
Dennis Tsilimingras, MD, MPH' , Jeffrey Schnipper, MD, MPH', Ashley Duke, DNP ${ }^{3}$, John Agens, $M D^{4}$, \\ Stephen Quintero, $M D^{3}$, Gail Bellamy, PhD ${ }^{5}$, James Janisse, $P h D^{7}$, Laura Helmkamp, MS ${ }^{7}$, and David \\ W. Bates, MD, MSc ${ }^{2}$
}

\begin{abstract}
'Department of Family Medicine \& Public Health Sciences, Wayne State University School of Medicine, Detroit, MI, USA; ${ }^{2}$ Division of General Medicine, Brigham and Women's Hospital and Harvard Medical School, Boston, MA, USA; ${ }^{3}$ Department of Family Medicine \& Rural Health, Florida State University College of Medicine and Tallahassee Memorial Hospital, Tallahassee, FL, USA; ${ }^{4}$ Department of Geriatrics, Florida State University College of Medicine and Tallahassee Memorial Hospital, Tallahassee, FL, USA; ${ }^{5}$ Department of Behavioral Sciences and Social Medicine, Florida State University College of Medicine, Tallahassee, FL, USA.
\end{abstract}

BACKGROUND: There has been little research to examine post-discharge adverse events (AEs) in rural patients discharged from community hospitals.

OBJECTIVE: We aimed to determine the rate of postdischarge AEs, classify the types of post-discharge AEs, and identify risk factors for post-discharge AEs in urban and rural patients.

DESIGN: This was a prospective cohort study of patients at risk for post-discharge adverse events from December 2011 through October 2012.

PATIENTS: Six hundred and eighty-four patients who were under the care of hospitalist physicians and were being discharged home, spoke English, and could be contacted after discharge, were admitted to the medical service. Patients were stratified as urban/rural using zip code of residence. Rural patients were oversampled to ensure equal enrollment of urban and rural patients.

MAIN MEASURES: The main outcome of the study was post-discharge AEs based on structured telephone interviews, health record review, and adjudication by two blinded, trained physicians using a previously established methodology.

RESULTS: Over $28 \%$ of 684 patients experienced postdischarge AEs, most of which were either preventable or ameliorable. There was no difference in the incidence of post-discharge AEs in urban versus rural patients (ARR $1.0495 \%$ CI $0.82-1.32$ ), but post-discharge AEs were associated with hypertension, type 2 diabetes mellitus, and number of secondary discharge diagnoses only in urban patients.

CONCLUSIONS: Post-discharge AEs were common in both urban and rural patients and many were preventable or ameliorable. Potentially different risk factors for AEs in urban versus rural patients suggests the need for further research into the underlying causes. Different

Prior Presentations Podium presentation at the American Public Health Association (APHA) Annual Meeting, 31 October 2012, San Francisco, California.

Poster Presentation at the Academy Health Annual Research Meeting, 24 June 2013, Baltimore, Maryland.

Received September 4, 2014

Revised February 5, 2015

Accepted February 18, 2015

Published online March 31, 2015 interventions may be required in urban versus rural patients to improve patient safety during transitions in care.

KEY WORDS: medical errors; adverse events; quality of care; transitional care.

J Gen Intern Med 30(8):1164-71

DOI: $10.1007 / \mathrm{s} 11606-015-3260-3$

(C) Society of General Internal Medicine 2015

\section{INTRODUCTION}

Post-discharge safety is a major public health concern for patients who transition from the hospital to home. ${ }^{1}$ The first study to examine post-discharge adverse events (AEs) identified a $19 \% \mathrm{AE}$ rate in urban patients discharged from the hospital's internal medicine service. ${ }^{2}$ A follow-up urban study identified a $23 \%$ rate of AEs. ${ }^{3}$ These AE rates are approximately five times higher than the rate of AEs that occur during a hospitalization, ${ }^{4,5}$ and were not reported by the Institute of Medicine (IOM) report, "To Err Is Human."

However, neither prior post-discharge study examined AEs involving a large number of both urban and rural patients discharged to home from a medical service run by hospitalist physicians of a community hospital. This is important, because $87 \%$ of hospitalized patients are cared for in community hospitals, ${ }^{7}$ at least $40 \%$ of community hospitals have hospitalist programs, ${ }^{8}$ and $35 \%$ of community hospitals serve rural patients. ${ }^{9}$ Moreover, rural patients are considered a priority population by the Agency for Healthcare Research and Quality because of potential disparities in care and relative lack of research in these patients. ${ }^{10}$ It is possible that the overall rate of AEs involving rural patients may be higher than the two urban studies, ${ }^{2,3}$ due to difficulties in access to care, lack of followup care in rural communities, and difficulties in transitional care between an urban provider and a rural patient's home. ${ }^{11}$

The objective of this study was to determine the incidence and types of AEs (including preventable and ameliorable AEs) in urban and rural patients in the month after discharge. A second objective was to examine the risk factors for postdischarge AEs in urban vs. rural patients, with a goal of further 
understanding underlying causes and possible interventions to improve patient safety in these different populations.

\section{METHODS}

\section{Setting, Participants, and Study Recruitment}

Eligible subjects for this prospective cohort study were recruited from Tallahassee Memorial Hospital (TMH) an academically affiliated community hospital of Florida State University (FSU), Tallahassee, Florida, from 14 December 2011, through 8 October 2012. We recruited adults admitted to the medical service, under the care of TMH hospitalist physicians, who were being discharged home, spoke English, and who could be contacted 30 days after discharge for a telephone interview. In the event that patients were unable to complete the telephone interview themselves, patient surrogates were permitted to complete the telephone interview. ${ }^{2,3}$ The study was approved by FSU, TMH, and Wayne State University institutional review boards.

Rural patients were defined by zip code of residence with a population density of less than or equal to 100 people per square mile. ${ }^{12}$ Potential subjects were identified from hospital administrative data. In order to ensure that equal proportions of urban and rural subjects were recruited, based on methods utilized in prior studies by these investigators, ${ }^{13}$ nursereviewers first stratified the patient list by urban/rural, then randomized the order in which potentially eligible patients from the list were approached to ensure unbiased patient enrollment, and finally over-sampled rural patients to ensure that equal proportions of urban and rural patients were recruited. Prior to discharge, nurse-reviewers obtained informed written consent from study subjects, including a release to allow researchers to review health records from other institutions in the month after discharge, and then administered a brief demographic survey regarding exposure variables difficult to obtain from health records, including education level, household income and living arrangements, transportation, and caregiver status.

\section{Telephone Interviews}

Nurse-reviewers made their first attempt to contact study patients by telephone within 3-4 weeks of discharge. If nurse-reviewers were unable to reach patients after ten attempts or within 6 weeks after discharge from the hospital, these patients were recorded as non-responders, and efforts to gather post-discharge health records were initiated. For these non-responders, we searched the TMH electronic health record to identify possible clinic visits, emergency department visits, and/or TMH readmissions. We also reviewed local newspapers for obituaries and the State of Florida Vital Statistics registry to assist in the identification of deceased patients. If a patient was contacted and declined study participation, that patient was recorded as withdrawn and excluded from the study.

The 20-minute telephone interview consisted of three components necessary for outcome assessment. The first component included the Care Transition Measure-3 questions addressing the patient's understanding of their health care needs and health management after discharge. ${ }^{14}$ The second component included questions to determine a patient's use of health services since discharge, including home care services, physician office or clinic visits, laboratory visits, emergency department visits, and readmissions to a hospital. If this utilization occurred outside the TMH system, additional contact information was obtained to allow researchers to obtain health records from these facilities. The third component consisted of a full review of organ systems, with questions addressing issues such as fever, pain or discomfort, inability to eat, nausea or vomiting, diarrhea, shortness of breath, cough, skin breakdown, rash, falls, swollen legs, urinary frequency, and dysuria. $^{2,3,15,16}$ If patients answered that any of these symptoms were new or worse since discharge, the nurse-reviewer asked additional follow-up questions regarding the severity of the symptoms, the timing of symptoms in relation to hospitalization and treatments, and the resolution of symptoms, in order to determine the relationship between these symptoms and health care delivery.

\section{Review of Health Records}

TMH outpatient health records were utilized to validate the telephone interview information provided by the patient and abstract additional information necessary for outcome measurement. Nurse-reviewers also contacted non-TMH health practices or institutions by fax and phone to collect paper health records for patients reportedly seen at these practices or institutions.

Next, nurse-reviewers combined information obtained from the telephone interview and/or the outpatient health records to screen for: 1) new or worsening symptoms; 2) unplanned health services utilization; and 3) abnormal laboratory test results. If nurse-reviewers identified any of the above information, they referred these cases to physician adjudicators who independently reviewed all information prepared by nurse-reviewers to determine the occurrence of postdischarge AEs. For cases for which nurse-reviewers could not identify any of the above information, they were recorded as negative for post-discharge AEs requiring no further review.

Two physician-adjudicators (J.A. and S.Q.) blinded to urban/rural status independently created case summaries for patients they identified with possible post-discharge AEs. ${ }^{2,3}$ One case summary was prepared for each possible AE. In each case, the same physician-adjudicators then rated their confidence that the patient injury was a result of medical management and not the patient's underlying medical conditions, including the absence of needed treatment when clearly clinically indicated, ${ }^{2,6}$ i.e., a post-discharge $\mathrm{AE}$, utilizing a scale of 
1 to $6(1$, little or no confidence; 2 , slight to moderate confidence; 3 , less than $50 \%$ confidence but a close call; 4 , more than $50 \%$ confidence but a close call; 5 , strong confidence; and 6 , virtually certain)., ${ }^{2,3,5}$ If their rating was 4,5 or 6 , the event was considered an AE. For AEs, the two independent physician-adjudicators then determined "preventability" and "ameliorability." Preventable means the injury would not have occurred at all had medical management been better, while ameliorable means the injury could have been lessened in severity or duration had the error not occurred. AEs were also categorized by effects on functional status, by severity (significant, serious, life-threatening, or fatal), ${ }^{17}$ duration, organ systems involved, and additional health care utilization (of note, an AE may be detected during a planned post-discharge physician visit and not the cause of any additional utilization). Lastly, we utilized a standard approach to classify the type of $\mathrm{AE}^{2-5}$ We utilized the Naranjo algorithm, which is a validated scoring system for determining attribution of symptoms to medications, ${ }^{18}$ previously modified by these investigators, ${ }^{15,16}$ as a guide for determining adverse drug events (ADEs). If there was disagreement between the two reviewers regarding causality (AE or not), preventability, or ameliorability, they discussed the case and attempted to come to consensus. If they could not reach consensus, a third independent physician-adjudicator (J.L.S.) reviewed the case and made a final decision. ${ }^{2,3}$

\section{Statistical Analysis}

We determined the proportion of urban and rural patients with post-discharge AEs and with preventable or ameliorable postdischarge AEs. We also determined the functional consequences of post-discharge adverse events, duration and severity of injury, health services utilization, and the different types of post-discharge AEs at the patient level. Chi-square tests and t-tests were utilized to test for differences in patient characteristics. Bivariate analyses compared various exposure variables and incidence of AEs. Subgroup analyses were conducted to determine factors associated with AEs in urban and rural patients, respectively. Multivariable log-binomial regression models were then built to determine the independent factors associated with the risk of experiencing a post-discharge $\mathrm{AE}$ at the patient level. We excluded several covariates from the final model that were not statistically significant. Reliability of adjudication was assessed by utilizing the kappa statistic for the reviewers' rating of post-discharge AEs. We utilized SAS, version 9.4 for all analyses (SAS Institute, Inc., Cary, North Carolina).

\section{RESULTS}

We identified 809 eligible urban and rural patients who agreed to participate in the study (Fig. 1). We excluded 96 patients because they were discharged to skilled nursing facilities or by non-hospitalist physicians, withdrew consent, or were discharged to hospice or died prior to discharge, and 29 patients were lost to follow-up. Physicians adjudicated 347 patients for possible AEs, 185 of 347 patients required discussion among the two adjudicators, and three of 185 patients required a third adjudicator. Outcomes were assessed for 684 patients (including 119 non-interviewed patients but for whom health records were available); urban patients were generally more educated, had higher household incomes, and utilized more private insurance, whereas rural patients more often had a diagnosis of type 2 diabetes mellitus (Table 1).

We identified 196 patients with post-discharge AEs, of which $98(28.8 \%)$ were urban and 98 (28.5\%) were rural patients (Table 2 and Fig. 1). Thus, the overall incidence of post-discharge AEs for all 684 patients was $28.7 \%$. The 196 patients with AEs experienced 290 separate post-discharge AEs. Of these 290 post-discharge AEs, 108 (37\%) were considered preventable and $105(36 \%)$ were ameliorable. Inter-rater reliability for assessment of post-discharge AEs was fair $(\mathrm{k}=0.53)$.

ADEs comprised 204 (70.3\%) of all 290 AEs (Table 2). Management errors and therapeutic errors were most often considered preventable, while procedural complications were least often considered preventable. There was a trend for rural patients to have a higher rate of ADEs and procedural

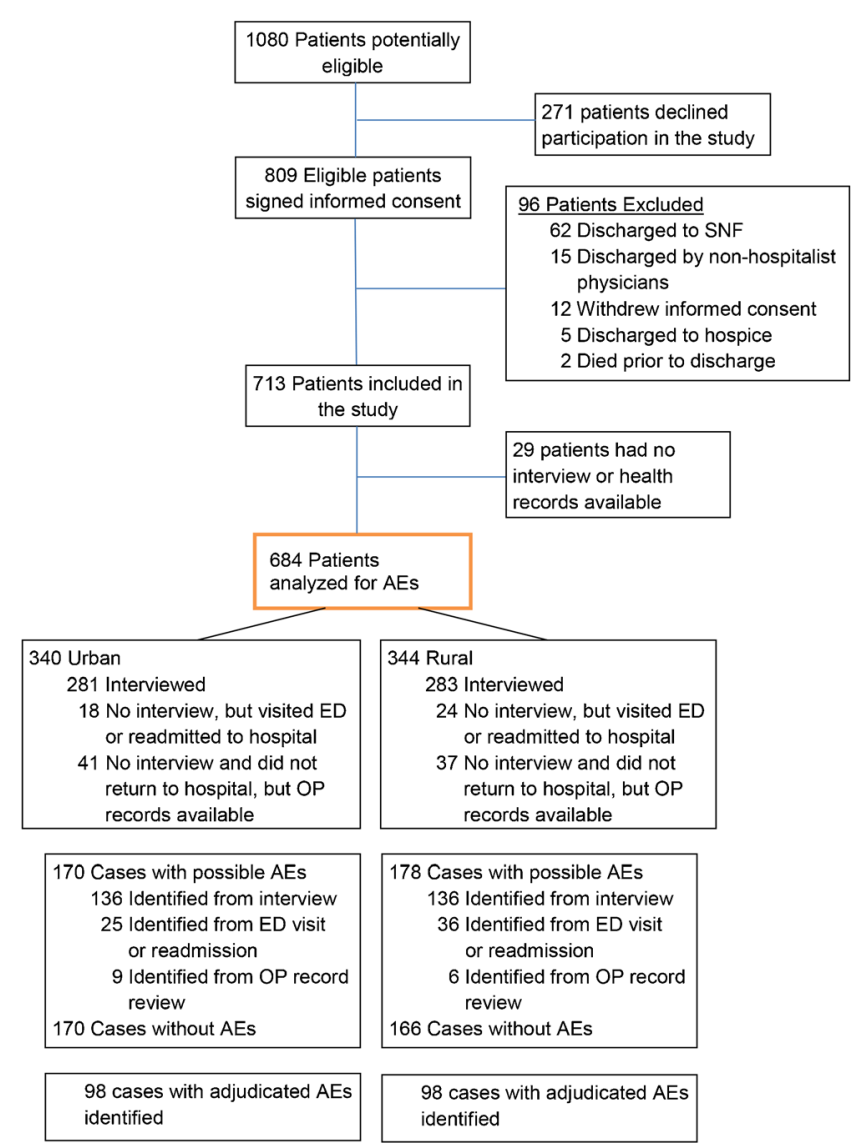

Figure 1. Flow of participants through the study. SNF=skilled nursing facility; $\mathrm{AEs}=$ adverse events; $\mathbf{E D}=$ emergency department; $\mathbf{O P}=$ outpatient. 
Table 1. Patient Characteristics

\begin{tabular}{|c|c|c|c|}
\hline Characteristic & Urban $(n=340)$ & Rural (n=344) & Significance ( $p$ value) \\
\hline \multicolumn{3}{|l|}{ Sex, No. } & 0.36 \\
\hline Female & $182(53.5 \%)$ & $172(50.0 \%)$ & \\
\hline Age, median (IQR) & $64.0(50.0-71.0)$ & $62.5(51.0-72.0)$ & 0.55 \\
\hline \multicolumn{3}{|l|}{ Race, No. $(\%)$} & 0.28 \\
\hline White & $263(78.7 \%)$ & $256(75.3 \%)$ & \\
\hline Black & $70(21.0 \%)$ & $83(24.4 \%)$ & \\
\hline \multicolumn{3}{|l|}{ Education, No. (\%) } & $<0.0001$ \\
\hline Less than High school & $16(4.8 \%)$ & $51(14.9 \%)$ & \\
\hline High school graduate & $89(26.5 \%)$ & $141(41.2 \%)$ & \\
\hline Some college/college graduate & $177(52.7 \%)$ & $134(39.2 \%)$ & \\
\hline Post-graduate & $54(16.1 \%)$ & $16(4.7 \%)$ & \\
\hline \multicolumn{3}{|l|}{ Household Income, No. (\%) } & $<0.0001$ \\
\hline$<\$ 25,000$ & $89(29.9 \%)$ & $147(49.2 \%)$ & \\
\hline$\$ 25,000-\$ 49,999$ & $70(23.5 \%)$ & $72(24.1 \%)$ & \\
\hline$\$ 50,000-\$ 74,999$ & $63(21.1 \%)$ & $46(15.4 \%)$ & \\
\hline$\$ 75,000+$ & $76(25.5 \%)$ & $34(11.4 \%)$ & \\
\hline \multicolumn{3}{|l|}{ Living situation, No. (\%) } & 0.55 \\
\hline Married or living as if married & $273(80.8 \%)$ & $284(82.6 \%)$ & \\
\hline Lives alone & $65(19.2 \%)$ & $60(17.4 \%)$ & \\
\hline Number of secondary discharge diagnoses, median (IQR) & $9(6-13)$ & $10(7-14)$ & 0.014 \\
\hline \multicolumn{3}{|l|}{ Payer, No. (\%) } & 0.0005 \\
\hline Private (= Blue cross,"commercial," "HMO”) & $145(43.0 \%)$ & $97(28.4 \%)$ & \\
\hline \multicolumn{4}{|l|}{ Government } \\
\hline Medicare (=medicare, medicare HMO) & $154(45.7 \%)$ & $191(56.0 \%)$ & \\
\hline Medicaid (=medicaid, medicaid HMO) & $20(5.9 \%)$ & $35(10.3 \%)$ & \\
\hline Self-pay & $18(5.3 \%)$ & $18(5.3 \%)$ & \\
\hline Hospital Stay, Number of days, median (IQR) & $3.0(2.0-4.5)$ & $3.0(2.0-4.0)$ & 0.36 \\
\hline Pneumonia & $41(12.1 \%)$ & $33(9.6 \%)$ & 0.30 \\
\hline \multicolumn{4}{|l|}{ Top five diagnoses } \\
\hline Hypertension & $246(72.4 \%)$ & $247(71.8 \%)$ & 0.87 \\
\hline Type 2 Diabetes Mellitus & $113(33.2 \%)$ & $146(42.4 \%)$ & 0.013 \\
\hline Atrial Fibrillation & $74(21.8 \%)$ & $75(21.8 \%)$ & 0.99 \\
\hline Coronary Artery Disease & $63(18.5 \%)$ & $72(20.9 \%)$ & 0.43 \\
\hline Infection & $62(18.2 \%)$ & $69(20.1 \%)$ & 0.54 \\
\hline
\end{tabular}

IQRinterquartile range

complications when compared to urban patients. Urban patients had a higher rate of management and therapeutic errors, but there were no differences in the frequencies of each $\mathrm{AE}$ type between rural and urban patients.

Health care utilization for urban and rural patients that experienced a post-discharge AE was similar (Table 3). Rehospitalizations and emergency department visits occurred in $24 \%$ and $34 \%$ of urban patients who suffered an $\mathrm{AE}$, respectively, and in $22 \%$ and $30 \%$ of rural patients. However, among the entire population, rehospitalizations occurred in $7 \%$ of urban and $6 \%$ of rural patients. The functional consequences of post- discharge AEs included predominantly mild effects on activities of daily living (ADLs) (Table 3), although almost one-third of patients with AEs suffered a major effect on ADLs. Over two-thirds of patients had an AE with a duration of over 1 week, and one-third of patients suffered a serious injury or worse. In general, the consequences, duration, and severity of post-discharge AEs were similar among urban and rural patients, although there was a nonsignificant trend towards longer duration among rural patients $(73.5 \%$ vs. $67.4 \%$ greater than 1 week, $p=0.3,5)$ and for anti-coagulants to more often be the cause of ADEs in rural patients $(12.2 \%$ vs. $7.1 \%, p=0.23)$.

Table 2. Post-Discharge adverse Events Categorized as Preventable, Ameliorable, or Neither for Urban and Rural Patients

\begin{tabular}{|c|c|c|c|c|c|c|}
\hline & Urban & & & Rural & & \\
\hline Patients with AEs & $98 / 340$ & & & $98 / 344$ & & \\
\hline Incidence Rate & $28.8 \%$ & & & $28.5 \%$ & & \\
\hline AEs* & 145 & & & 145 & & \\
\hline Preventable/ Ameliorable & Prev & Amel & Non P/A & Prev & Amel & Non P/A \\
\hline Overall & $56(39 \%)$ & $57(39 \%)$ & $32(22 \%)$ & $52(36 \%)$ & $48(33 \%)$ & $45(31 \%)$ \\
\hline Adverse Drug Events & $29 / 100(29 \%)$ & $45 / 100(45 \%)$ & $26 / 100(26 \%)$ & $29 / 104(28 \%)$ & $36 / 104(35 \%)$ & $39 / 104(38 \%)$ \\
\hline Management Errors & $18 / 24(75 \%)$ & $3 / 24(13 \%)$ & $3 / 24(13 \%)$ & $14 / 18(78 \%)$ & $3 / 18(17 \%)$ & $1 / 18(6 \%)$ \\
\hline Procedural Complications & $3 / 9(33 \%)$ & $3 / 9(33 \%)$ & $3 / 9(33 \%)$ & $2 / 14(14 \%)$ & $7 / 14(50 \%)$ & $5 / 14(36 \%)$ \\
\hline Therapeutic Errors & $5 / 8(63 \%)$ & $3 / 8(38 \%)$ & $\begin{array}{l}0 / 8 \\
(0 \%)\end{array}$ & $4 / 4(100 \%)$ & $0 / 4(0 \%)$ & $0 / 4(0 \%)$ \\
\hline Diagnostic Errors & $1 / 4(25 \%)$ & $3 / 4(75 \%)$ & $0 / 4(0 \%)$ & $3 / 4(75 \%)$ & $1 / 4(25 \%)$ & $0 / 4(0 \%)$ \\
\hline Hospital Acquired Infections & $0 / 0$ & $0 / 0$ & $0 / 0$ & $0 / 1(0 \%)$ & $1 / 1(100 \%)$ & $0 / 1(0 \%)$ \\
\hline
\end{tabular}

* The number of adverse events exceeds the number of unique patients with adverse events because patients can have more than one adverse event. AEs adverse events; Prevpreventable adverse events; Amelameliorable adverse events; Non P/Aneither preventable nor ameliorable 
Table 3. Health Care Utilization, Functional Consequences, Duration and Severity of Injury, Symptoms, and Drug Classes Associated with Post-Discharge Adverse Events

\begin{tabular}{|c|c|c|}
\hline & Urban & Rural \\
\hline Total subjects & 340 & 344 \\
\hline Subjects experiencing any $\mathbf{A E}$ & $98(28.8 \%)$ & $98(28.5 \%)$ \\
\hline Outcome & N (\% of AE patients) & $\mathbf{N}(\%$ of AE patients) \\
\hline \multicolumn{3}{|l|}{ Health care utilization: ${ }^{*}$} \\
\hline Readmission to Hospital & $24(24.5 \%)$ & $22(22.4 \%)$ \\
\hline Visit to ED & $33(33.7 \%)$ & $29(29.6 \%)$ \\
\hline Visit to diagnostic facility & $4(4.1 \%)$ & $1(1.0 \%)$ \\
\hline Planned visit to MD office & $39(39.8 \%)$ & $37(37.8 \%)$ \\
\hline Unplanned visit to MD office & $10(10.2 \%)$ & $9(9.2 \%)$ \\
\hline Telephone MD office & $8(8.2 \%)$ & $6(6.1 \%)$ \\
\hline \multicolumn{3}{|l|}{ Functional consequences of AEs: ${ }^{\dagger}$} \\
\hline Symptoms only & $24(24.5 \%)$ & $30(30.9 \%)$ \\
\hline Mild effects on ADLs & $41(41.8 \%)$ & $37(38.1 \%)$ \\
\hline Major effects on ADLs & $32(32.6 \%)$ & $28(28.9 \%)$ \\
\hline \multirow{2}{*}{\multicolumn{3}{|c|}{ Duration of injury associated with AEs: ${ }^{2}$}} \\
\hline & & \\
\hline Up to 1 day of symptoms & $9(9.2 \%)$ & $7(7.1 \%)$ \\
\hline $1-3$ days of symptoms & $11(11.2 \%)$ & $9(9.2 \%)$ \\
\hline 4-7 days of symptoms & $12(12.2 \%)$ & $10(10.2 \%)$ \\
\hline$>1$ week of symptoms & $66(67.4 \%)$ & $72(73.5 \%)$ \\
\hline \multicolumn{3}{|c|}{ Severity of injury associated with AEs: ${ }^{\dagger}$} \\
\hline Significant & $65(66.3 \%)$ & $66(68.0 \%)$ \\
\hline Serious & $31(31.6 \%)$ & $25(25.8 \%)$ \\
\hline Life-threatening & $1(1.0 \%)$ & $4(4.1 \%)$ \\
\hline Fatal & $1(1.0 \%)$ & $2(2.1 \%)$ \\
\hline \multicolumn{3}{|l|}{ Symptoms associated with AEs: ${ }^{*}$} \\
\hline Gastrointestinal & $29(29.6 \%)$ & $30(30.6 \%)$ \\
\hline Neuropsychiatric & $20(20.4 \%)$ & $16(16.3 \%)$ \\
\hline Cardiovascular & $21(21.4 \%)$ & $22(22.4 \%)$ \\
\hline Respiratory & $7(7.1 \%)$ & $8(8.2 \%)$ \\
\hline Other & $56(57.1 \%)$ & $56(57.1 \%)$ \\
\hline \multicolumn{3}{|l|}{ Drug categories implicated in ADEs: } \\
\hline Cardiovascular & $26(26.5 \%)$ & $19(19.4 \%)$ \\
\hline Anti-infectives & $17(17.4 \%)$ & $19(19.4 \%)$ \\
\hline Anti-coagulants & $7(7.1 \%)$ & $12(12.2 \%)$ \\
\hline Steroids & $6(6.1 \%)$ & $7(7.1 \%)$ \\
\hline Opioids & $5(5.1 \%)$ & $6(6.1 \%)$ \\
\hline Analgesics & $4(4.1 \%)$ & $5(5.1 \%)$ \\
\hline Diuretics & $2(2.0 \%)$ & $5(5.1 \%)$ \\
\hline
\end{tabular}

*Health care utilization percentages sum to more than $100 \%$ because patients may have experienced multiple adverse events, and because a single adverse event may result in the utilization of multiple types of care

${ }^{*}$ For functional consequences, duration, and severity of injury, the results are presented as the most severe outcome for all AEs suffered by an individual patient ${ }^{*}$ Symptoms reported by patient, physician, or both. Certain patients have multiple symptoms per AE or multiple AEs

EDemergency department, MDphysician, AEsadverse events, ADLsactivities of daily living, ADEsadverse drug events

In the bivariate analysis, the number of secondary discharge diagnoses $(p \leq 0.01)$, hypertension $(p=0.01)$, and type 2 diabetes mellitus $(\mathrm{p}=0.02)$ were significant for urban patients in predicting post-discharge AEs (Table 4), while primary discharge diagnosis $(\mathrm{p}=0.04)$ and coronary artery disease $(\mathrm{p}=0.03)$ were significant predictors for rural patients. However, in only three cases was there evidence of effect modification by urban/rural status based on the $p$ value of the interaction term: number of secondary diagnoses $(\mathrm{p}=0.03)$, hypertension $(\mathrm{p}=0.01)$, and diabetes $(\mathrm{p}=0.05)$.

In the multivariable log-binomial complete adjusted cohort analysis, urban versus rural residency status was not significantly associated with risk for post-discharge AEs (ARR 1.04, $95 \%$ CI 0.82 -1.32) (Table 5). In subgroup analyses, we found that an increase in a patient's number of secondary diagnoses increased the risk of post-discharge AEs among urban patients (ARR $1.0595 \%$ CI 1.02-1.08), but not among rural patients (ARR $0.9995 \%$ CI $0.97-1.02, \mathrm{p}$ for interaction=0.008) (Table 5). Interestingly, there was also evidence of effect modification for a primary diagnosis of gastrointestinal disease, with a nonsignificant trend towards being a positive predictor in urban patients and a negative predictor in rural patients ( $\mathrm{p}$ for interaction $=0.05$ ).

\section{DISCUSSION}

In this study, the largest to date to examine post-discharge AEs in both urban and rural patients, we found that more than $28 \%$ of patients suffered a post-discharge AE and over two-thirds of AEs were considered preventable or ameliorable. AE rates were almost identical in urban versus rural patients, with urban patients showing a stronger relationship between number of secondary diagnoses and AE risk than rural patients. We found the rate of post-discharge AEs to be higher than previous studies $(19 \%$ and $23 \%){ }^{2,3}$ While this may be due to temporal trends or differences in the health systems or patient populations, the difference may also be in the extensive review of 
Table 4. Patient Characteristics With and Without Post-Discharge Adverse Events

\begin{tabular}{|c|c|c|c|c|c|c|c|}
\hline \multirow[b]{2}{*}{ Overall count $(\%)$} & \multicolumn{3}{|l|}{ Urban } & \multicolumn{3}{|l|}{ Rural } & \multirow{5}{*}{$\begin{array}{l}\text { Interaction } \\
\mathbf{P}\end{array}$} \\
\hline & \multicolumn{3}{|c|}{$340(49.7 \%)$} & \multicolumn{3}{|c|}{$344(50.3 \%)$} & \\
\hline & $\mathbf{A E}$ & No AE & & $\mathbf{A E}$ & No AE & & \\
\hline Overall count $(\%)$ & $\begin{array}{l}98(28.8 \\
\%)\end{array}$ & $\begin{array}{l}242(71.2 \\
\%)\end{array}$ & & $\begin{array}{l}98(28.5 \\
\%)\end{array}$ & $\begin{array}{l}246(71.5 \\
\%)\end{array}$ & & \\
\hline \multicolumn{3}{|l|}{ Characteristics } & \multicolumn{3}{|l|}{$\mathbf{p}$} & $\mathbf{p}$ & \\
\hline \multicolumn{8}{|l|}{ Sex, $N(\%)$} \\
\hline Female & $58(59.2 \%)$ & $124(51.2 \%)$ & 0.19 & $52(53.1 \%)$ & $120(48.8 \%)$ & 0.47 & 0.66 \\
\hline \multirow{2}{*}{\multicolumn{8}{|c|}{ Race, N (\%) }} \\
\hline & & & & & & & \\
\hline White & $76(80.8 \%)$ & $187(78.2 \%)$ & 0.63 & $72(74.2 \%)$ & $184(76.0 \%)$ & 0.72 & 0.53 \\
\hline African American & $18(19.2 \%)$ & $52(21.8 \%)$ & & $25(25.8 \%)$ & $58(24.0 \%)$ & & \\
\hline \multicolumn{8}{|l|}{ Education, N (\%) } \\
\hline$<$ High school & $4(4.1 \%)$ & $12(5.0 \%)$ & 0.58 & $14(14.4 \%)$ & $37(15.1 \%)$ & 0.88 & 0.58 \\
\hline High school graduate & $29(29.9 \%)$ & $60(25.1 \%)$ & & $40(41.2 \%)$ & $101(41.2 \%)$ & & \\
\hline Some college/ college grad & $52(53.6 \%)$ & $125(52.3 \%)$ & & $37(38.1 \%)$ & $97(39.6 \%)$ & & \\
\hline \multirow{2}{*}{\multicolumn{8}{|c|}{ Household Income, N (\%) }} \\
\hline & & & & & & & \\
\hline$<\$ 25,000$ & $26(29.9 \%)$ & $63(29.9 \%)$ & 0.49 & $45(50.6 \%)$ & $102(48.6 \%)$ & 0.89 & 0.83 \\
\hline$\$ 25,000-\$ 49,999$ & $17(19.5 \%)$ & $53(25.2 \%)$ & & $19(21.4 \%)$ & $53(25.2 \%)$ & & \\
\hline$\$ 50,000-\$ 74,999$ & $17(19.5 \%)$ & $46(21.8 \%)$ & & $15(16.8 \%)$ & $31(14.8 \%)$ & & \\
\hline$\$ 75,000+$ & $27(31.0 \%)$ & $49(23.2 \%)$ & & $10(11.2 \%)$ & $24(11.4 \%)$ & & \\
\hline \multicolumn{8}{|l|}{ Living Situation, N (\%) } \\
\hline Married or living as if married & $79(81.4 \%)$ & $194(80.5 \%)$ & 0.84 & $84(85.7 \%)$ & $200(81.3 \%)$ & 0.89 & 0.56 \\
\hline Lives alone & $18(18.6 \%)$ & $47(19.5 \%)$ & & $14(14.3 \%)$ & $46(18.7 \%)$ & & \\
\hline \multicolumn{8}{|l|}{ Primary Discharge Diagnosis, N (\%) } \\
\hline Circulatory & $10(10.2 \%)$ & $23(9.5 \%)$ & 0.87 & $15(15.3 \%)$ & $26(10.6 \%)$ & 0.04 & 0.33 \\
\hline Respiratory & $29(29.6 \%)$ & $90(37.2 \%)$ & & $33(33.7 \%)$ & $93(37.8 \%)$ & & \\
\hline Gastrointestinal & $25(25.5 \%)$ & $55(22.7 \%)$ & & $11(11.2 \%)$ & $54(22.0 \%)$ & & \\
\hline Genitourinary & $5(5.1 \%)$ & $8(3.3 \%)$ & & $2(2.0 \%)$ & $8(3.3 \%)$ & & \\
\hline Infectious & $8(8.2 \%)$ & $14(5.8 \%)$ & & $11(11.2 \%)$ & $12(4.9 \%)$ & & \\
\hline Musculoskeletal & $3(3.1 \%)$ & $7(2.9 \%)$ & & $3(3.1 \%)$ & $14(5.7 \%)$ & & \\
\hline Neurovascular & $11(11.2 \%)$ & $32(13.2 \%)$ & & $17(17.4 \%)$ & $33(13.4 \%)$ & & \\
\hline Other & $7(7.1 \%)$ & $13(5.4 \%)$ & & $6(6.1 \%)$ & $6(2.4 \%)$ & & \\
\hline $\begin{array}{l}\text { Number of Secondary Discharge Diagnoses, } \\
\text { mean (SD) }\end{array}$ & $11.0(5.2)$ & $9.3(4.8)$ & $<0.01$ & $10.8(5.2)$ & $10.8(5.9)$ & 0.98 & 0.03 \\
\hline \multicolumn{8}{|l|}{ Payer, N (\%) } \\
\hline Private Institution & $42(43.3 \%)$ & $103(42.9 \%)$ & 0.70 & $27(28.1 \%)$ & $70(28.6 \%)$ & 0.89 & 0.96 \\
\hline \multicolumn{8}{|l|}{ Government } \\
\hline Medicare & $47(48.4 \%)$ & $107(44.6 \%)$ & & $56(58.3 \%)$ & $135(55.1 \%)$ & & \\
\hline Medicaid & $4(4.1 \%)$ & $16(6.7 \%)$ & & $8(8.3 \%)$ & $127(11.0 \%)$ & & \\
\hline Self-Pay & $4(4.1 \%)$ & $14(5.8 \%)$ & & $5(5.2 \%)$ & $13(5.3 \%)$ & & \\
\hline Hospital stay, mean (SD) & $4.1(3.4)$ & $3.5(2.1)$ & 0.11 & $3.6(2.2)$ & $3.9(3.6)$ & 0.52 & 0.10 \\
\hline Pneumonia, N (\%) & $16(16.3 \%)$ & $25(10.3 \%)$ & 0.12 & $9(9.2 \%)$ & $24(9.8 \%)$ & 0.87 & 0.28 \\
\hline \multicolumn{8}{|l|}{ Top five diagnoses } \\
\hline Hypertension, N (\%) & $80(81.6 \%)$ & $166(68.6 \%)$ & 0.01 & $66(67.4 \%)$ & $181(73.6 \%)$ & 0.25 & 0.01 \\
\hline Type 2 Diabetes Mellitus, N (\%) & $42(42.9 \%)$ & $71(29.3 \%)$ & 0.02 & $40(40.8 \%)$ & $106(43.1 \%)$ & 0.70 & 0.05 \\
\hline Atrial Fibrillation, $\mathbf{N}(\%)$ & $21(21.4 \%)$ & $53(21.9 \%)$ & 0.92 & $23(23.5 \%)$ & $52(21.1 \%)$ & 0.64 & 0.69 \\
\hline Coronary Artery Disease, N (\%) & $18(18.4 \%)$ & $45(18.6 \%)$ & 0.96 & $28(28.6 \%)$ & $44(17.9 \%)$ & 0.03 & 0.13 \\
\hline Infection, N (\%) & $21(21.4 \%)$ & $41(16.9 \%)$ & 0.33 & $25(25.5 \%)$ & $44(17.9 \%)$ & 0.11 & 0.69 \\
\hline
\end{tabular}

Interaction $p$ indicates whether the effect of the characteristic on a patient's risk of experiencing an adverse event differs between urban and rural patients

outpatient health records in the present study; such differences were used to explain higher rates of post-discharge ADEs in a different study ${ }^{13}$ Consistent with previous studies is the finding that the majority of post-discharge AEs are preventable or ameliorable.

Interestingly, the number of secondary discharge diagnoses was more strongly associated with AE risk in urban than in rural patients. This phenomenon may be explained by the fact that rural patients are less likely to seek health care utilization, as shown by other studies, ${ }^{19,20}$ and therefore less likely to receive a prompt secondary diagnosis when compared to urban patients who more frequently utilize the health care system. Supporting evidence for this theory may be found in hypertension and diabetes diagnoses that are associated with regular health care and were only associated with $\mathrm{AE}$ risk in urban patients. A trend towards more management and therapeutic errors among urban patients suggests that these patients may be more medically complex. On the other hand, several nonsignificant findings provide hints at access-to-care issues among rural patients: rural patients had a trend toward longer duration of AEs and more ADEs due to anticoagulation, which require regular monitoring to prevent.

Few studies have evaluated post-discharge AEs in rural patients. ${ }^{2,3}$ Studies of rural patient safety have focused almost exclusively on inpatient medical errors and AEs. ${ }^{21,22}$ The potential for post-discharge AEs is conceivably greater for 
Table 5. Multivariable Model for Urban and Rural Patient Risk of Experiencing a Post-Discharge Adverse Event *

\begin{tabular}{|c|c|c|c|c|c|}
\hline \multirow[t]{2}{*}{ Parameter } & \multicolumn{2}{|l|}{ Complete Cohort } & \multicolumn{3}{|l|}{ Subgroup Cohorts } \\
\hline & $\begin{array}{l}\mathrm{ARR}^{\dagger}(95 \% \mathrm{CI}) \text { in } \\
\text { All Patients }\end{array}$ & $\begin{array}{l}\mathbf{p} \\
\text { value }\end{array}$ & $\begin{array}{l}\text { ARR }(95 \% \text { CI }) \text { in } \\
\text { Urban Patients }\end{array}$ & $\begin{array}{l}\text { ARR (95\% CI) in } \\
\text { Rural Patients }\end{array}$ & $\begin{array}{l}\text { p value for } \\
\text { interaction term* }\end{array}$ \\
\hline Urban (vs. rural) & $1.04(0.82,1.32)$ & 0.74 & NA & NA & \\
\hline $\begin{array}{l}\text { Primary Diagnosis } \\
\text { (vs. respiratory) }\end{array}$ & & 0.18 & & & 0.19 \\
\hline Circulatory & $1.35(0.92,1.97)$ & 0.13 & $1.32(0.73,2.41)$ & $1.41(0.86,2.32)$ & 0.88 \\
\hline Gastrointestinal & $1.00(0.70,1.42)$ & 0.99 & $1.36(0.87,2.13)$ & $0.63(0.34,1.17)$ & 0.05 \\
\hline Infectious & $1.68(1.12,2.52)$ & 0.01 & $1.56(0.83,2.92)$ & $1.94(1.13,3.29)$ & 0.60 \\
\hline Neurovascular & $1.18(0.81,1.72)$ & 0.38 & $1.06(0.59,1.90)$ & $1.29(0.79,2.10)$ & 0.61 \\
\hline Other & $1.26(0.86,1.85)$ & 0.24 & $1.49(0.89,2.49)$ & $1.08(0.61,1.93)$ & 0.42 \\
\hline Female & $1.12(0.99,1.26)$ & 0.07 & $1.20(1.02,1.43)$ & $1.10(0.93,1.30)$ & 0.43 \\
\hline Age & $1.00(0.99,1.01)$ & 0.78 & $1.00(0.99,1.01)$ & $1.00(0.99,1.01)$ & 0.91 \\
\hline Number of Secondary & $1.02(1.00,1.04)$ & 0.10 & $1.05(1.02,1.08)$ & $0.99(0.97,1.02)$ & 0.008 \\
\hline Discharge Diagnoses & & & & & \\
\hline Sample size & 684 & & 340 & 344 & \\
\hline Log Likelihood & -403.09 & & -196.53 & -199.37 & \\
\hline
\end{tabular}

*The multivariable model outcome indicates whether or not a patient experienced at least one adverse event. The multivariable model was specified as logbinomial to provide relative risk estimates ${ }^{\dagger} A R R=$ Adjusted Relative Risk ${ }^{*}$ The $p$ values for the interaction term indicate whether the effect of the covariate on a patient's risk of experiencing an adverse event differs between urban and rural patients

poor and underserved populations, including those residing in small rural communities. However, in our study we did not identify a difference in the rate of post-discharge AEs when we compared urban to rural patients. As in previous studies, we identified ADEs as the most common type of post-discharge AEs. ${ }^{2,3}$ Other types of AEs that we reported, unlike the previous post-discharge studies, ${ }^{2,3}$ included management errors, which were the second most common AE type.

The multivariable subgroup analysis found evidence of effect modification by number of secondary diagnoses (which was a significant predictor in urban patients, but not in rural patients) and by primary diagnosis of gastrointestinal disease (which trended towards a positive predictor in urban patients and a negative predictor in rural patients). Further investigation is needed to determine the robustness of these findings.

Our study had several limitations. We were not able to interview $17 \%$ of patients for outcome assessment, basing our results on post-discharge health records alone. However, our results did not change appreciably when the non-interviewed patients were removed from the analysis. It is difficult to determine the direction of loss to follow-up bias in this study, because patients may be unavailable for reasons unrelated or related to study outcomes. For these patients, we relied on the review of health records to determine the occurrence of post-discharge AEs. In other cases, we were unable to obtain health records to corroborate and supplement information provided during postdischarge phone interviews. Our results may have been confounded by the fact that rural patients may have bypassed a local hospital for a facility with more advanced care, which may explain the higher number of secondary diagnoses among rural patients. However, we adjusted for several measures of complexity in our models. Our study was limited to Englishspeaking patients. This may have limited the generalizability of our study, but not the internal validity, since less than $2 \%$ of patients were excluded for this reason. The effect modification results did not adjust for multiple testing, and therefore may be overstated. In addition, the study may have been underpowered for certain predictors. Both of these issues can be addressed with additional research. The outcomes assessment process is theoretically prone to interviewer bias, and instrument and misclassification bias, which can bias toward the null hypothesis. ${ }^{23-25}$ However, while the nurse-reviewers were not blinded to urban/ rural status, they used a structured interview guide and patient summary process. ${ }^{15,16}$ Furthermore, physician-adjudicators were blinded to residence status, rigorously trained, and with co-adjudication by two physicians (and a third if necessary). Lastly, recall bias was addressed by corroborating all patient reports to the health record.

Future studies should probe in more depth the reasons for differences in $\mathrm{AE}$ risk factors among urban versus rural patients, especially regarding issues of access to health care and monitoring of medical conditions. If our findings are corroborated, they may suggest potential customization of interventions to improve transitions of care based on residential status. Finally, while the proportion of readmissions that is truly preventable is controversial, ${ }^{26}$ the data demonstrating the high rate of preventability of post-discharge AEs are more consistent across studies, thus justifying the need for the effective implementation of interventions to improve patient safety during transitions of care.

Acknowledgements: We thank Leslee Hancock for assistance with data collection and Henry Carretta, PhD, for statistical assistance.

Role of the Sponsor: The funding agency had no role in the design and conduct of the study; collection, management, analysis, and interpretation of the data; and preparation, review, or approval of the manuscript; and decision to submit the manuscript for publication.

Conflict of Interest Disclosures: Dr. Schnipper is the recipient of a grant from Sanofi-Aventis for an investigator-initiated study of intensive discharge interventions to improve outcomes in patients with diabetes discharged on insulin. 
Grant Support: This work is supported by an RO1 award from the Agency for Healthcare Research and Quality (grant R01HSO18694 to Dr. Tsilimingras).

Disclaimer: The content is solely the responsibility of the authors and does not necessarily represent the official views of the Agency for Healthcare Research and Quality.

Author Contributions: Conception and design: Tsilimingras, Schnipper, Duke, Bates.

Analysis and interpretation of the data: Tsilimingras, Schnipper, Duke, Bates, Janisse, Helmkamp.

Drafting of the article: Tsilimingras, Schnipper, Duke.

Critical revision of the article for important intellectual content: Tsilimingras, Schnipper.

Final approval of the article: All authors.

Provision of study materials or patients: Tsilimingras, Schnipper, Duke. Statistical expertise: Janisse, Helmkamp.

Obtaining of funding: Tsilimingras

Administrative, technical, or logistic support: Tsilimingras, Schnipper, Duke.

Collection and assembly of data: Tsilimingras, Schnipper, Duke, Janisse, Helmkamp.

Corresponding Author: Dennis Tsilimingras, MD, MPH; Department of Family Medicine Public Health SciencesWayne State University School of Medicine, Detroit, MI 48201, USA (e-mail: dtsilimi@ med.wayne.edu).

\section{REFERENCES}

1. Tsilimingras D, Bates DW. Addressing postdischarge adverse events: a neglected area. Jt Comm J Qual Patient Saf. 2008;34:85-97.

2. Forster AJ, Murff HJ, Peterson JF, Gandhi TK, Bates DW. The incidence and severity of adverse events affecting patients after discharge from the hospital. Ann Intern Med. 2003;138:161-167.

3. Forster AJ, Clark HD, Menard A, et al. Adverse events among medical patients after discharge from hospital. CMAJ. 2004; 170:345-349.

4. Thomas EJ, Studdert DM, Burstin HR, et al. Incidence and types of adverse events and negligent care in Utah and Colorado. Med Care. 2000;38:261-271.

5. Leape LL, Brennan TA, Laird N, et al. The nature of adverse events in hospitalized patients. Results of the Harvard Medical Practice Study II. N Engl J Med. 1991;324:377-384.

6. Kohn LT, Corrigan JM, Donaldson MS, eds. To Err is Human: Building a safer Health System. Washington DC: National Academy Press; 1999.

7. American Hospital Association. "AHA Hospital Statistics, 2014 Edition."
8. Wachter RM. The state of hospitalist medicine in 2008. Med Clin N Am. 2008;92:265-273.

9. American Hospital Association. "AHA Hospital Statistics, 2013 Edition."

10. http://www.ahrq.gov/health-care-information/priority-populations/index.html, Accessed 01/30/15.

11. Institute of Medicine, Committee on the Future of Rural Health, Board on health Care Services. Quality Through Collaboration: The Future of Rural Health. Washington, DC: National Academy Press; 2005.

12. http://www.floridahealth.gov/ \%5C/programs-and-services/communityhealth/rural-health/index.html, Accessed 01/30/15.

13. Schnipper JL, et al. Rationale and design of the pharmacist intervention for low literacy in cardiovascular disease (PILL-CVD) study. Circ Cardiovasc Qual Outcomes. 2010;3:212-219.

14. Parry C, Mahoney E, Chalmers SA, Coleman EA. Assessing the quality of transitional care: further applications of the care transitions measure. Med Care. 2008;46:317-322.

15. Schnipper JL, Kirwin JL, Cotugno MC, et al. Role of pharmacist counseling in preventing adverse drug events after hospitalization. Arch Intern Med. 2006;166(5):565-571.

16. Kripalani S, Roumie CL, Dalal AK, et al. Effect of a Pharmacist Intervention on Clinically Important Medication Errors After Hospital Discharge: A Randomized Trial. Ann Intern Med. 2012;157(1):1-10.

17. Bates DW, Cullen DJ, Laird N, et al. Incidence of adverse drug events and potential adverse drug events. Implications for prevention. ADE Prevention Study Group. JAMA. 1995;274(1):29-34.

18. Naranjo CA, Busto U, Sellers EM, et al. A method for estimating the probability of adverse drug reactions. Clin Pharmacol Ther. 1981;30(2):239-245.

19. Bennett KJ, Bellinger JD, Probst JC. Receipt of Influenza and Pneumonia Vaccinations: The Dual Disparity of Rural Minorities. J Am Geriatr Soc. 2010;58(10): 1896-1902

20. Goodridge D, Lawson J, Rennie D, Marciniuk D. Rural/urban differences in health care utilization and place of death for persons with respiratory illness in the last year of life. Rural Remote Health. 2010;10(2): 1349

21. Casey M, Wakefield M, Coburn AF, Moscovice IS, Loux S. Prioritizing Patient Safety Interventions in Small and Rural Hospitals. Jt Comm Qual Patient Saf. 2006;32:693-702.

22. Longo DR, Hewett JE, Ge B, Schubert S. Rural hospital patient safety systems implementation in two states. J Rural Health. 2007;23:189 197.

23. Hayward RA, Hofer TP. Estimating hospital deaths due to medical errors: preventability is in the eye of the reviewer. JAMA. 2001;286:415-420.

24. Sanazaro PJ, Mills DH. A critique of the use of generic screening in quality assessment. JAMA. 1991;265:1977-1981

25. Caplan RA, Posner KL, Cheney FW. Effect of outcome on physician judgments of appropriateness of care. JAMA. 1991;265:1957-1960.

26. van Walraven C, Bennett C, Jennings A, Austin PC, Forster AJ. Proportion of hospital readmissions deemed avoidable: a systematic review. CMAJ. 2011;183(7):E391-E402. 